\title{
Presence of Mycoplasma Spp. in Patients with Asthma or Allergic Rhinitis
}

\author{
Muñoz-Zurita Guillermo ${ }^{*}$, Paz Martínez David2, Yáñez Santos Jorge Antonio ${ }^{3}$, \\ Gil Juárez Constantino ${ }^{4}$, Cedillo Ramírez María Lilia ${ }^{5}$ \\ ${ }^{1}$ Alumno de Doctorado del Posgrado en Ciencias Ambientales, Benemérita Universidad Autónoma de Puebla, \\ Puebla, Mexico \\ ${ }^{2}$ Hospital Universitario de Puebla, Benemérita Universidad Autónoma de Puebla, Puebla, Mexico \\ ${ }^{3}$ Facultad de Estomatología, Benemérita Universidad Autónoma de Puebla, Puebla, Mexico \\ ${ }^{4}$ Centro de Investigaciones en Ciencias Microbiológicas, Benemérita Universidad Autónoma de Puebla, Puebla, \\ Mexico \\ ${ }^{5}$ Centro de Detección Biomolecular, VIEP, Benemérita Universidad Autónoma de Puebla, Puebla, Mexico \\ Email: ${ }^{*}$ guimuzu2003@yahoo.com
}

Received 2 May 2014; revised 7 June 2014; accepted 9 July 2014

Copyright (C) 2014 by authors and Scientific Research Publishing Inc.

This work is licensed under the Creative Commons Attribution International License (CC BY). http://creativecommons.org/licenses/by/4.0/

(c) (i) Open Access

\begin{abstract}
Objective: To compare the presence of Mycoplasma spp. in pharyngeal swabs of patients with asthma, allergic rhinitis and controls, also to compare the reactivity to allergens in the three groups. Material and Methods: Throat swabs of 120 patients with asthma, 211 allergic rhinitis patients and 171 healthy persons were cultured in E media. Positive cultures were identified by PCR. Susceptibility of patients positive for isolation of Mycoplasma spp. to indoor, forest and undergrowth allergens were determined. Results: Mycoplasma spp. was isolated in $26.6 \%$ of samples from asthmatic patients, $36 \%$ in patients with allergic rhinitis and $2.9 \%$ in the group of healthy persons. Positive patients for Mycoplasma with asthma and allergic rhinitis showed susceptibility tomite, grass and thunder mainly. Conclusion: There is a higher incidence of Mycoplasma spp. in asthmatic and allergic rhinitis patients than healthy persons. Only patients with asthma or allergic rhinitis showed reactivity to environmental allergens.
\end{abstract}

\section{Keywords}

Asthma, Allergic Rhinitis, Allergens, Mycoplasma Spp.

\footnotetext{
${ }^{*}$ Corresponding author.
}

How to cite this paper: Guillermo, M.-Z., David, P.M., Antonio, Y.S.J., Constantino, G.J. and Lilia, C.R.M. (2014) Presence of Mycoplasma Spp. in Patients with Asthma or Allergic Rhinitis. Advances in Microbiology, 4, 720-725. 


\section{Introduction}

Asthma is a syndrome characterized by bronchoconstriction, smooth muscle contraction, mucous hypersecretion and local swelling of the respiratory tract [1] [2]. The swelling may be induced or exacerbated by microorganisms and allergens. Clinical asthmatic exacerbations have been associated with bacterial and viral respiratory tract infections [3].

The concept that asthma is associated with differences in the composition of this microbiome is now accepted; what is not clear is whether the differences in microbial community composition themselves mediate pathologic changes in the airways or whether they reflect differences in systemic immune function [4]. Mycoplasmas are common agents of respiratory tract infections. An infection with $M$. pneumonia may precede the onset of asthma or exacerbate asthma symptoms. Chronic infection with $M$. pneumonia has been suspected to play a part in some patients with asthma. The role of immunoglobulin E-related hypersensitivity and induction of T helper type 2 immune response leading to inflammatory response in $M$. pneumoniae-infected patients with asthma have also been proposed [5]. Mycoplasma fermentans has also been found in the respiratory tract of asthmatic patients [6].

\section{Objective}

The purpose of this study was to compare the presence of Mycoplasma spp. in pharyngeal swabs of patients with asthma, allergic rhinitis and controls, also to compare the reactivity to allergens in the three groups.

\section{Materials and Methods}

\subsection{Patients and Controls}

First, One hundred and twenty wheezing asthmatic patients who came to the Allergy Service of the Puebla University Hospital were included in the study. Asthma was diagnosed if there was hyperreactivity of the bronchi manifested by an improvement in airway obstruction of $15 \%$ to $20 \%$ after administration of an inhaled adrenergic agent. A throat swab was taken from each patient when wheezing was observed in order to isolate mycoplasmas. Two hundred and eleven patients with allergic rhinitis who came to the Allergy Service of the Puebla University Hospital were included in the study. Allergic rhinitis was diagnosed by the allergist doctor. All patients with allergic rhinitis did not have asthma. A throat swab was taken during the acute phase of the allergic rhinitis. The study was performed from November 2011 to December 2013. All patients and controls signed an informed consent form and the protocol was approved by the Ethics Committee of the Puebla University Hospital. Patients and controls lived in the State of Puebla, Mexico and are demographically considered as mestizos.

One hundred and seventy one healthy relatives of the patients were considered as controls, a throat swab was taken in order to isolate mycoplasmas.

\subsection{Detection of Mycoplasmas}

Throat swabs were put in Eaton media (E media) with penicillin and incubated at $37^{\circ} \mathrm{C}$ for 30 days or until phenol red indicator changed color. Throat swabs were reported as negative when they failed to change color of the $\mathrm{pH}$ indicator after 30 days of incubation. As soon as the color changed, broth cultures were seeded on $\mathrm{E}$ agar plates and PCR were performed in order to detect mycoplasmas. DNA was obtained from positive cultures.

A Polymerase Chain Reaction (PCR) test was used to confirm the presence of mycoplasmas in blood. The oligonucleotide primers used for PCR detection were a) AR1: 5’ ATG RGG RTG CGG CGT ATT AG 3’y; b) AR2: 5' CKG CTG GCA CAT AGT TAG CCRT 3', (where K represents a mixture of nucleotides G_T and R contains A-G), which amplified a 301-nucleotide specific gene sequence that exist in the genome of 30 mycoplasma species [7]. Before we used this PCR based test to detect Mycoplasma, we confirmed the specificity of these primers.

The reaction mixture contained $50 \mathrm{mM} \mathrm{KCl}, 1.5 \mathrm{mM} \mathrm{MgCl}_{2}, 10 \mathrm{mM}$ Tris-HCL (pH 8.3), $0.2 \mathrm{mM}$ of each deoxynucleotide triphosphate, $6 \mu \mathrm{M}$ of each primer and 1 unit of AmpliTaq ${ }^{\circledR}$ (Perkin Elmer Cetus, Emerville, CA.) in a total volume of $50 \mu \mathrm{l}$. The sample to be analyzed ( $5 \mu \mathrm{l}$ ) was always added last. A diluted lysate of $M$. fermentans PG-18 corresponding to $100 \mathrm{CCU}$ and sterile water were used as positive and negative controls respectively. The amplification involved 40 cycles, each consisted of denaturation at $95^{\circ} \mathrm{C}$ for $25 \mathrm{~s}$, primers annealing at $60^{\circ} \mathrm{C}$ for $60 \mathrm{~s}$ and extension at $72^{\circ} \mathrm{C}$ for $60 \mathrm{~s}$. The amplified products were analyzed by electrophoresis in $2 \%$ agarose gels and visualized by UV light after Ethidium bromide staining. 


\subsection{Sensitivity to Allergens}

Skin tests to determine sensitivity to allergens (Prick test) were performed to patients positive for Mycoplasma spp. Three types of allergens were tested: indoor allergens (mites, cockroaches, dog and cat hair), forest allergens (eucalyptus, pine, oak, pepper tree, willow, Alamo and thunder tree) and undergrowth allergens (sunflower, neat's tongue, pasture, thistle and epazote).

\section{Results}

Skin Fifty four male asthmatic patients and sixty six female asthmatic patients were tested in order to detect Mycoplasma spp. Ninety three male patients and one hundred and eighteen female patients with allergic rhinitis were included in this study. Seventy males and one hundred and one females without signs and symptom of asthma or allergic rhinitis were considered as controls. Mycoplasma spp. was detected in $26.6 \%$ of asthmatic patients, in $36 \%$ of patients who suffered allergic rhinitis and in $2.9 \%$ of controls. There was not statistical difference $\left(X^{2} p>0.05\right)$ in the percentage of isolation of mycoplasmas in females and males in asthmatic patients, patients with allergic rhinitis or controls. (Figures 1-3 Resolution of figures was increased to 300 pixels.) There was statistical difference in the percentage of isolation of mycoplasmas between patients with allergic rhinitis and controls (Kruskal Wallis test $p<0.05$ ). There was not statistical difference in the percentage of isolation of mycoplasmas between asthmatic patients and patients with allergic rhinitis (Kruskal Wallis test $p>0.05$ ).

The sensitivity to allergens was determined in patients and controls positive for Mycoplasma spp. The results showed that asthmatic patients were more reactive to mites and cockroaches (indoor allergens), to pepper tree and thunder tree (forest allergens) and pasture and neat's tongue (undergrowth allergens). Patients with allergic rhinitis were more sensitive to mites (indoor allergens), Alamo tree, thunder and eucalyptus tree (forest allergens) and pasture and thistle tree (undergrowth allergens). Controls were negative to allergens tested.

\section{Discussion}

Microorganism and allergens play an important role in the pathogenesis of asthma because they induce an inflammatory response. Exacerbations of asthma are primarily caused by viral and atypical bacterial infections. Rhinoviruses are the most common viruses detected after an asthma exacerbation. Atypical bacterial infections from Mycoplasma and Chlamydia have also been linked to chronic asthma and potential asthma exacerbations [8] [9].

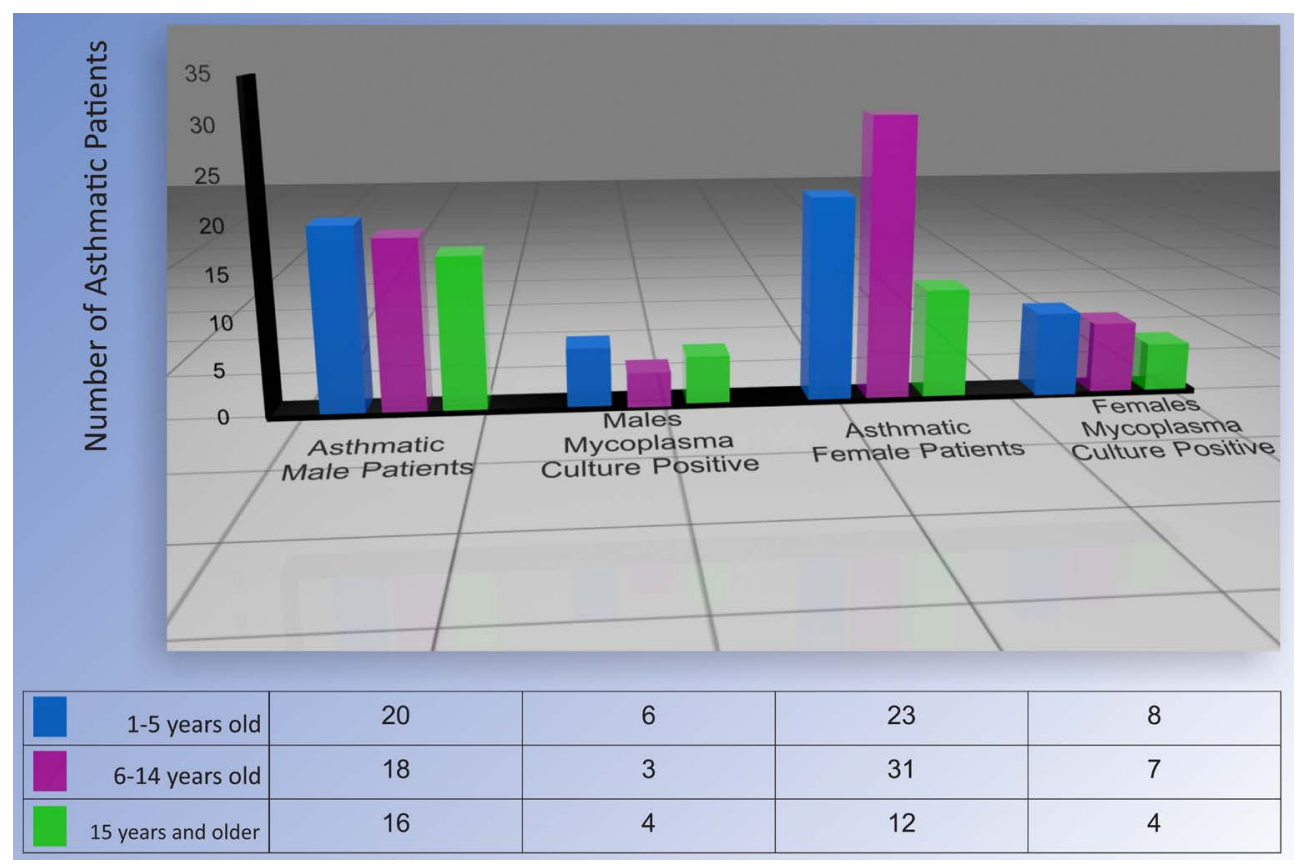

Figure 1. Presence of Mycoplasma spp. in asthmatic patients. 


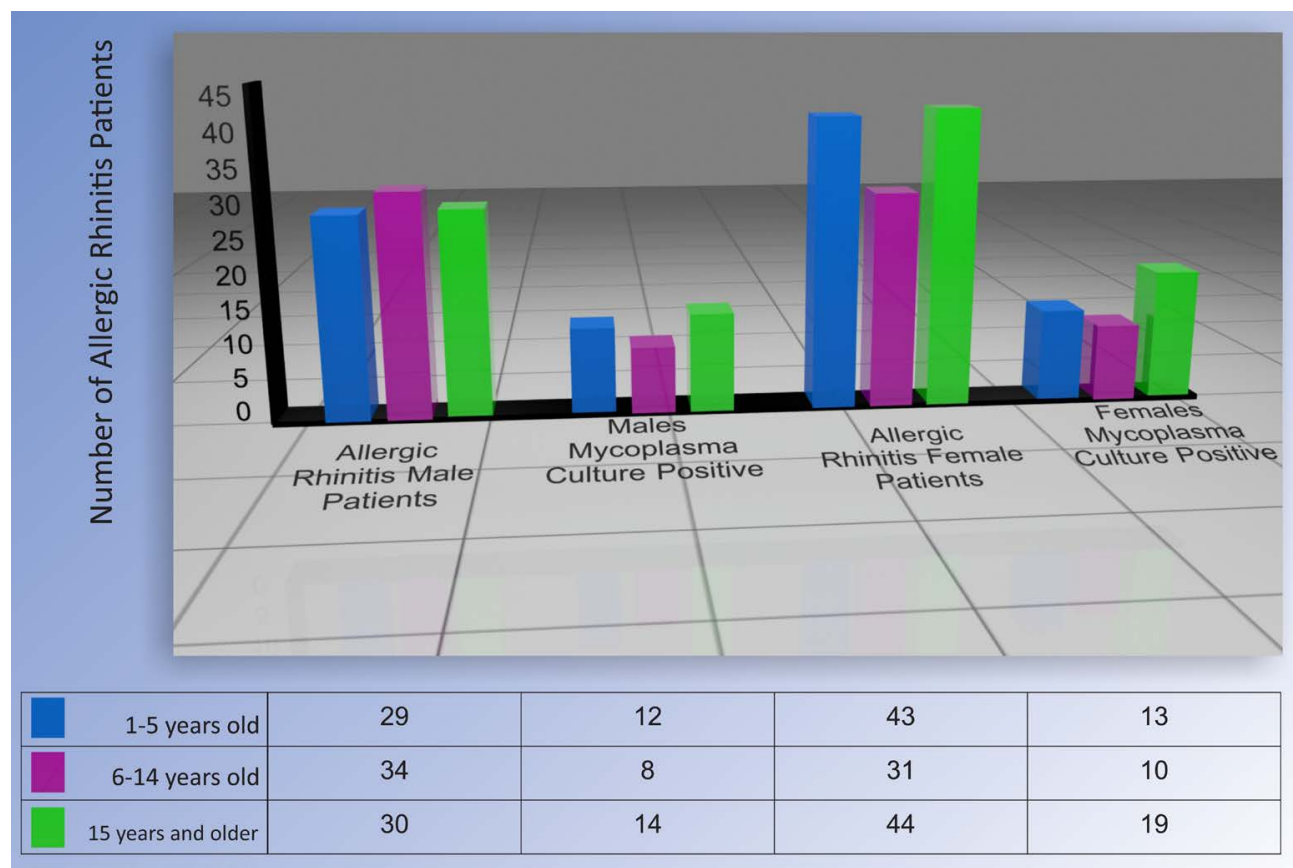

Figure 2. Presence of Mycoplasma spp. in allergic rhinitis patients.

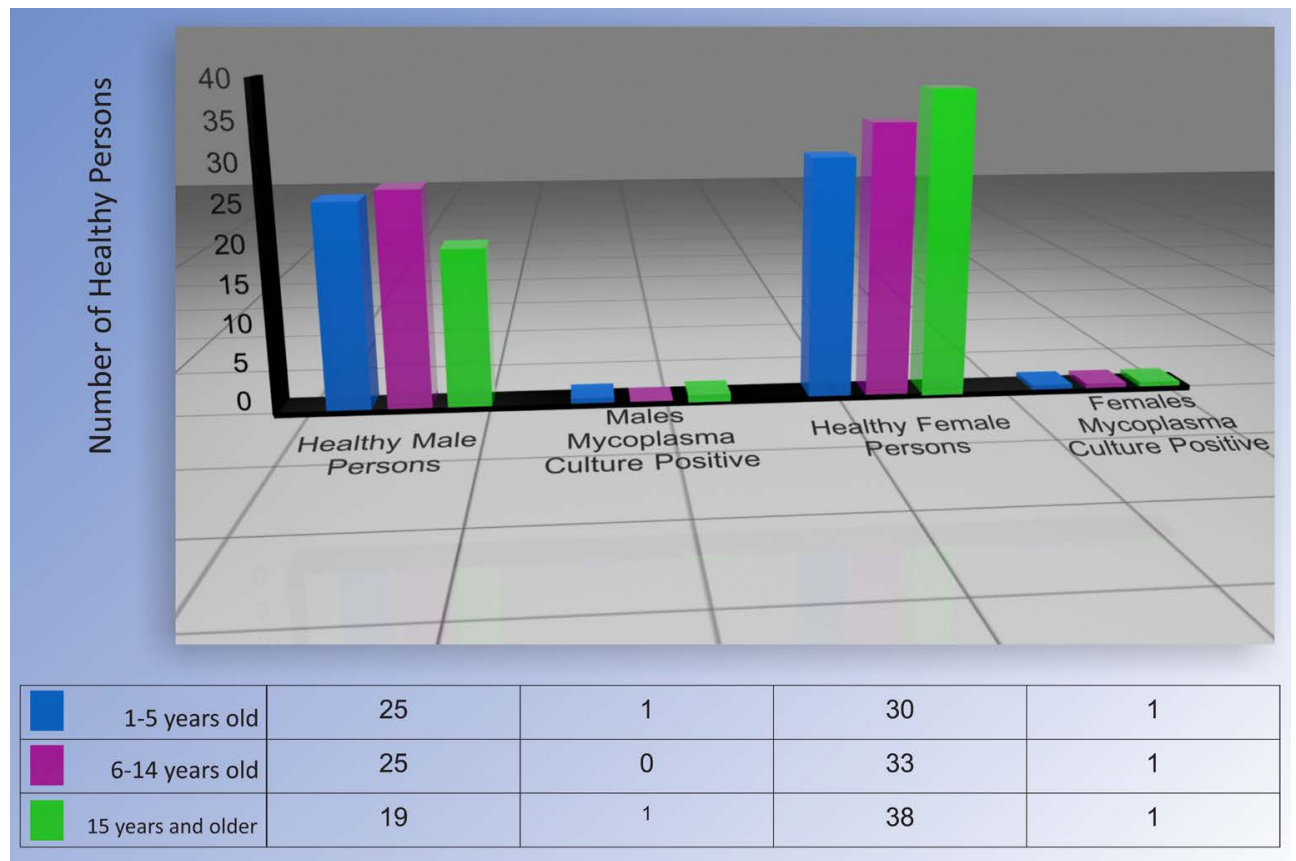

Figure 3. Presence of Mycoplasma spp. in Healthy Persons.

Mycoplasmas have been associated with chronic infectious diseases in several animal species including man [10]. Mycoplasmas are able to stimulate as well as suppress lymphocytes in a non-specific polyclonal manner. Mycoplasmas and mycoplasma-derived cell components modulate the activities of monocytes, macrophages and NK cells and trigger the production of a wide variety of upregulating and downregulating cytokines [10]. Over 20 Mycoplasma spp. have been shown to induce the production of proinflammatory cytokines tumor necrosis factor, interleukin 1 (IL 1), and IL6, chemokines such as IL8, monocyte chemoattractant protein 1, macrophage inflammatory protein 1 , granulocyte monocyte colony stimulating factors as well as prostaglandins and nitric oxide [11]. 
These abilities shown by mycoplasmas support the possible role of these microorganisms in asthma. There are evidences that suggest the role of Mycoplasma pneumoniae in asthma exacerbation and possibly as a factor in the pathogenesis of asthma [12]-[15].

Mycoplasma fermentans has been detected in the respiratory tract of asthmatic patients [6] so we decided to search for Mycoplasma spp. in this study. Our results showed that Mycoplasma spp. was isolated in 26.6\% of samples from asthmatic patients and $2.9 \%$ in the group of healthy persons. These results are according to other studies about the role of mycoplasmas in asthma, although the exact contribution to asthma development and or persistence remains to be determined. Evidence from human studies links both Mycoplasma pneumoniae and Chlamydophila pneumoniae to new onset wheezing, exacerbations of prevalent asthma and long term decrements in lung function, suggesting that the organisms can play an important role in the natural history of asthma. Animal models of acute and chronic infections with the bacteria indicate that they have the ability to modulate allergic sensitization and pulmonary physiologic and immune response to allergen challenge [16]. Allergic sensitization and respiratory symptoms on exposure to allergen form an integral part of the clinical spectrum of asthma in many children and adults. This is a reason why we determine the sensitivity to allergens in this study.

Rhinitis is broadly defined as inflammation of the nasal mucosa. It is a common disorder that affects up to $40 \%$ of the population. Allergic rhinitis is the most common type of chronic rhinitis, affecting $10 \%$ to $20 \%$ of the population, and evidence suggests that the prevalence of the disorder is increasing. Severe allergic rhinitis has been associated with significant impairments in quality of life, sleep and work performance [17]. In this study we found that $36 \%$ of patients with allergic rhinitis were positive for Mycoplasma spp. The results suggest that mycoplasma colonization may be favored in patients with allergic rhinitis.

Allergens play an important role in the development of asthma and allergic rhinitis. Some studies have shown that the majority of the skin prick test positive patients are less than 10 years old [18]. Rhinitis was the most common symptom in positive skin prick test persons whether associated or not with asthma and or conjunctivitis [19]. The main contribution of this study is that Mycoplasma spp. is frequently isolated in patients with allergic rhinitis without asthma.

Since this study was done with Mexican population, it is important to perform more studies in different demographic populations in order to determine the role of mycoplasmas in asthma and allergic rhinitis.

\section{Acknowledgements}

Allergy Service of the Puebla University Hospital, CONACYT and Daniel Arenas.

\section{References}

[1] Kim, H. and Mazza, J. (2011) Asthma. Allergy, Asthma \& Clinical Immunology, 7, S2.

[2] Fox, S.I. (2011) In Fisiología Humana. 12th Edition, Mc Graw Hill, México, 537-538.

[3] Zozarri, M.E. and Buss, W.W. (1990) The Role of Respiratory Infections in Airway Responsiveness and the Pathogenesis of Asthma. Immunology and Allergy Clinics of North America, 10, 449-461.

[4] Huang, Y.J. and Boushey, H.A. (2014) The Microbioma and Asthma. Annals of the American Thoracic Society, 11, S48-S51. http://dx.doi.org/10.1513/AnnalsATS.201306-187MG

[5] Nisar, N., Guleria, R., Kumar, S., Chawla, T.C. and Biswas, N.R. (2007) Mycoplasma pneumoniae and Its Role in Asthma. Postgraduate Medical Journal, 83, 100-104. http://dx.doi.org/10.1136/pgmj.2006.049023

[6] Gil, J.C., Maldonado, M.G., Zenteno, E., Yáñez, S.J.A., Paz, D. and Cedillo, L. (1999) Detección de micoplasmas en pacientes con asma. Revista Instituto Nacional Enfermedades Respiratorias, 12, 113-119.

[7] Sidhu, M.K., Rashidbaigi, A., Testa, D. and Lia, M.J. (1995) Competitor Internal Standards for Quantitative Detection of Mycoplasma DNA. FEMS Microbiology Letters, 128, 207-211. http://dx.doi.org/10.1111/j.1574-6968.1995.tb07524.x

[8] Newcomb, D.C. and Stokes, P. (2009) Bugs and Asthma. A Different Disease? Proceedings of the American Thoracic Society, 6, 266-271. http://dx.doi.org/10.1513/pats.200806-056RM

[9] Lieberman, D., Lieberman D., Printz, S., Yaakov, B., Lazrovich, Z., Ohana, B., Friedman, M.G., Dvoskin, B., Leinonen, M. and Boldur, I. (2002) Atypical Pathogen Infection in Adults with Acute Exacerbation of Bronchial Asthma. American Journal of Respiratory and Critical Care Medicine, 167, 407-410.

[10] Razin, S. and Hayflick, L. (2010) Highligths of Mycoplasma Research-An Historical Perspective. Biologicals, 38, 183-190. http://dx.doi.org/10.1016/j.biologicals.2009.11.008 
[11] Rottem, S. (2003) Interaction of Mycoplasmas with Host Cells. Physiological Reviews, 83, 417-432.

[12] Gil, J.C., Cedillo, R.L., Mayagoitia, B.G. and Paz, M.D. (1993) Isolation of Mycoplasma pneumoniae from Asthmatic Patients. Annals of Allergy, 70, 23-25.

[13] Kraft, M., Cassell, G., Henson, J.A., Watson, H., Williamson, J., Marmion, B., Gaydos, C. and Martin, R. (1998) Detection of Mycoplasma pneumoniae in the Airways of Adults with Chronic Asthma. American Journal of Respiratory and Critical Care Medicine, 158, 998-1001. http://dx.doi.org/10.1164/ajrccm.158.3.9711092

[14] Martin, R.J., Chu, H.W., Honour, J.M. and Harbeck, R.J. (2001) Airway Inflammation and Bronchial Hyperresponsiveness after Mycoplasma pneumoniae Infection in a Murine Model. American Journal of Respiratory Cell and Molecular Biology, 24, 577-582. http://dx.doi.org/10.1165/ajrcmb.24.5.4315

[15] Medina, J.L., Coalson, J., Brooks, E., Winter, V., Chaparro, A., Principe, M., Kannan, T., Baseman, J. and Dube, P. (2012) Mycoplasma pneumoniae CARDS Toxin Induces Pulmonary Eosinophilic and Lymphocytic Inflammation. American Journal of Respiratory Cell and Molecular Biology, 46, 815-822. http://dx.doi.org/10.1165/rcmb.2011-0135OC

[16] Sutherland, E. and Martin, R. (2007) Asthma and Atypical Bacterial Infection. Chest, 132, 1962-1966. http://dx.doi.org/10.1378/chest.06-2415

[17] Small, P. and Kim, H. (2011) Allergic Rhinitis. Allergy, Asthma \& Clinical Immunology, 7, S3. http://dx.doi.org/10.1186/1710-1492-7-S1-S3

[18] Hendrick, D., Davies, R., D’Souza, M. and Pepys, J. (1975) An Analysis of Skin Prick Test Reactions in 656 Asthmatic Patients. Thorax, 30, 2-8. http://dx.doi.org/10.1136/thx.30.1.2

[19] D’Amato, G., Chatzigeorgiou, G., Corsico, R., et al. (1997) Evaluation of the Prevalence of Skin Prick Test Positivity to Alternaria and Cladosporium in Patients with Suspected Respiratory Allergy. Allergy, 52, 711-716. http://dx.doi.org/10.1111/j.1398-9995.1997.tb01227.x 
Scientific Research Publishing (SCIRP) is one of the largest Open Access journal publishers. It is currently publishing more than 200 open access, online, peer-reviewed journals covering a wide range of academic disciplines. SCIRP serves the worldwide academic communities and contributes to the progress and application of science with its publication.

Other selected journals from SCIRP are listed as below. Submit your manuscript to us via either submit@scirp.org or Online Submission Portal.
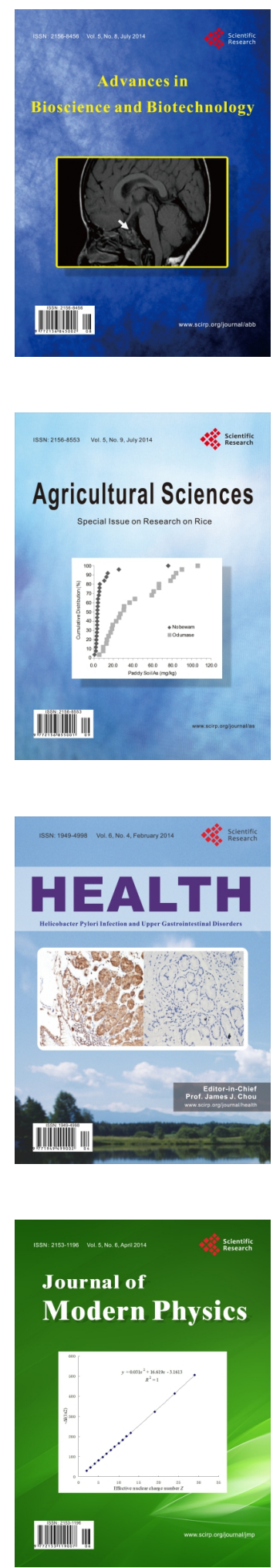
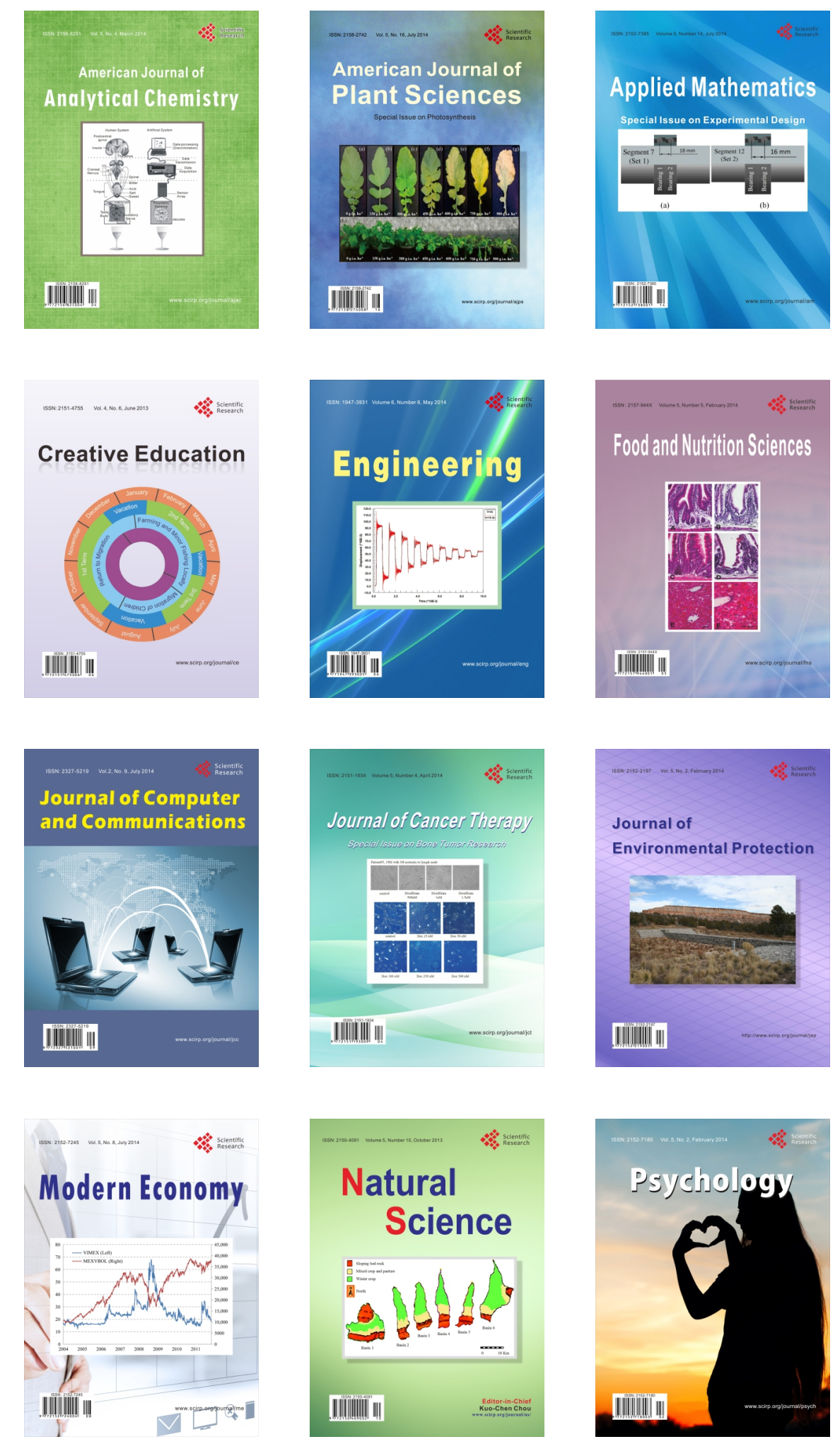